\title{
Development and validation of RP-HPLC method for determination of Duloxetine hydrochloride in bulk and dosage form
}

\author{
*Chusena Narasimharaju Bhimanadhuni ${ }^{1}$, Devala Rao Garikapati ${ }^{2}$, Chintha Srinivas ${ }^{3}$ \\ ${ }^{1}$ Research Scholar, Department of Pharmaceutical Analysis, Prist University, Thanjavur, Tamilnadu, India \\ ${ }^{2}$ Department of Pharmaceutical Analysis, K.V.S.R Siddhartha College of Pharmaceutical Sciences, Vijayawada, \\ Krishna(Dt), Andhra Pradesh, India \\ ${ }^{3}$ Department of Pharmaceutical Analysis, Browns College of Pharmacy, Khammam, Andhra Pradesh, India
}

\begin{abstract}
A reverse phase high performance liquid chromatographic method was developed for the determination of duloxetine hydrochloride in bulk and dosage form. The separation was effected on a kromasil ODS $\mathrm{C}_{18}$ column $(250 \mathrm{~mm} X 4.6 \mathrm{~mm}, 5 \mu)$ using a mobile phase mixture of buffer and methanol in a ratio of 85:15 v/v at a flow rate of $1.0 \mathrm{ml} / \mathrm{min}$. The detection was made at $230 \mathrm{~nm}$. The retention time of duloxetine hydrochloride was found to be $3.443 \pm 0.06 \mathrm{~min}$. Calibration curve was linear over the concentration range of $20-120 \mu \mathrm{g} / \mathrm{ml}$ of duloxetine hydrochloride. The propose method was validated as per the ICH guidelines. The method was accurate, precise, specific and rapid found to be suitable for the quantitative analysis of the drug and dosage form.
\end{abstract}

Key Words: Method development and validation, duloxetine hydrochloride, Tablets, Kromasil C18 column, RP-HPLC.

\section{INTRODUCTION}

Duloxetine hydrochloride (+)-(s)-N-methyl-3-(1napthyloxy)-3-(thiophen-2-yl)-propan-1-amine (The Merck Index, 2001) is a potential dual inhibitor of the reuptake of serotonin and norepinephrine. It has been approved by the US Food and Drug administration for the treatment of major depressive disorder and for the diabetic peripheral neuropathic pain. It belongs to the class narcoleptics. Literature survey reveals that only a few methods based on RP-HPLC method were developed and validated for the determination of duloxetine hydrochloride in pharmaceutical dosage forms (Dasari et al., 2010). Few others are: LC-tandem mass spectrometry method for the determination of duloxetine in human plasma (Senthamil et al., 2007), stability indicating RP-HPLC method for the duloxetine (Dahivelkar et al., 2010), metabolism, excretion and pharmacokinetics of duloxetine in healthy human subjects (Lantz et

\footnotetext{
*Corresponding Author:

Ch Narasimha Raju Bh, Department of Pharmaceutical analysis Annabattuni Satya Narayana Pharmacy College

Burripalem Road, Tenali-522201

Guntur (Dt), Andhra Pradesh

E-mail:bhchnraju@yahoo.com
}

al., 2003), duloxetine hydrochloride in Pharmaceutical formulation by HPLC with UV detection (Lakshmana et al., 2010), spectrophotometric method in ultraviolet region for the determination of duloxetine hydrochloride in bulk and in pharmaceutical formulations (Yunoos et al., 2010), spectrophotomatric method for quantification of duloxetine hydrochloride in capsule dosage form (Raj et al., 2011), liquid chromatography-mass spectrometric (LC/MS) method for the determination of duloxetine in human plasma using flupentixol as the internal standard (Ma et al., 2007), determination of duloxetine in human plasma by HPLC with column switching and ultraviolet spectroscopy (Waldschmitt et al., 2007), analysis of the duloxetine in human plasma after solid-phase extraction procedure (SPE) (Mercolini et al., 2007), HPTLC method for its estimation as bulk drug and its tablet dosage form (Dhaneshwar et al., 2008) etc. Duloxetine hydrochloride is being marketed in both domestic and international market. No official method has been found in any of the pharmacopoeia. The present investigation by the author describes a rapid, accurate and precise RP-HPLC method for the determination of the drug from bulk sample and 
pharmaceutical dosage form. The detector responses were linear in the concentration range of 20$120 \mu \mathrm{g} / \mathrm{ml}$ of drug. The method was validated as per ICH guidelines.

\section{EXPERIMENTAL}

\section{Chromatographic conditions}

Shimadzu high pressure liquid chromatographic instrument provided with a kromasil ODS $\mathrm{C}_{18}$ column $(250 \mathrm{mmX} 4.6 \mathrm{~mm}, 5 \mu)$ and LC 20 AD Pump and Prominence SPD 20A UV-deuterium detector was employed in the study. A 20 $\mu \mathrm{L}$ Hamilton injection syringe was used for sample injection (Bhimanadhuni et al, 2012). Data acquisition was performed by using Spinchrome software, Shimadzu Class VP version 6.12 SPS data system. HPLC grade methanol and water were purchased from E. Merck Co, Mumbai, India and Potassium dihydrogen phosphate and ortho phosphoric acid AR grade were purchased from SD Fine Chem Mumbai, India.

\section{Drug samples}

The reference sample and branded formulation of duloxetine hydrochloride was supplied by M/s Orchid Pharmaceuticals, Chennai, India.

\section{Mobile phase}

Accurately $1.36 \mathrm{~g}$ of potassium dihydrogen phosphate was weighed out and dissolved in $550 \mathrm{ml}$ of water. $0.3 \mathrm{~g}$ of dihydrogen potassium phosphate was weighed out and dissolved in $450 \mathrm{ml}$ of water. Both solutions were mixed to prepare buffer solution. The solution was filtered through $0.45 \mu \mathrm{m}$ membrane filter and was degassed (Bhimanadhuni et al, 2012). A freshly prepared binary mixture of buffer:Methanol in a ratio of $(85: 15) \mathrm{V} / \mathrm{V}$ was used as the mobile phase. Methanol was used as diluent for preparing the working solution of the drug. The mobile phase was filtered through $0.05 \mu$ membrane filter and sonicated by using Power Sonicator (Model 405), Hwashin Technology, Korea before use. The flow rate of the mobile phase was maintained at $1 \mathrm{ml} / \mathrm{min}$. The column temperature was maintained at $25^{\circ} \mathrm{C}$ and the detection of the drug was carried out at $230 \mathrm{~nm}$.

\section{Stock and working standard solution}

About 25mg of duloxetine hydrochloride was weighed accurately and transferred into $25 \mathrm{ml}$ vo-

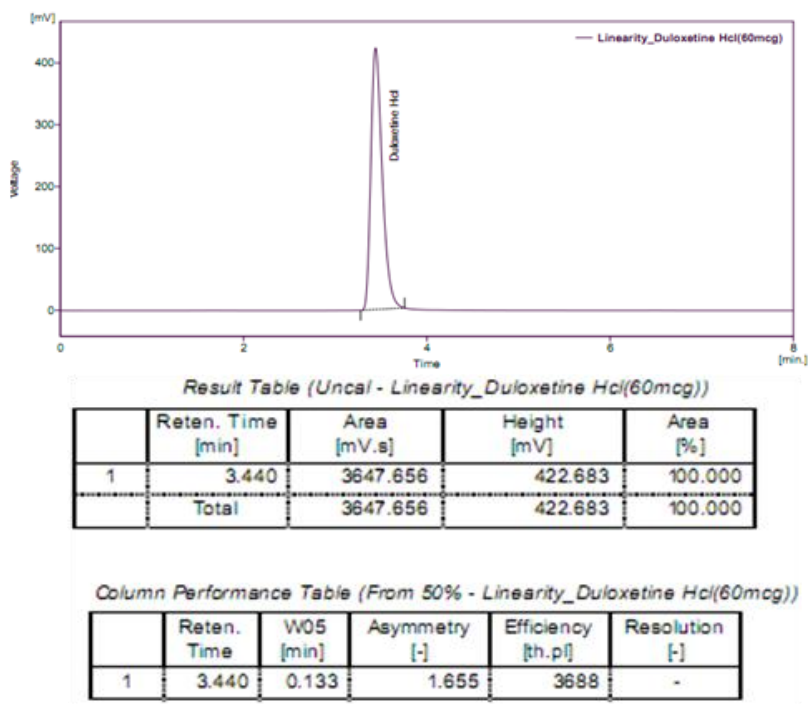

Figure 1: Chromatogram of duloxetine hydrochloride $60 \mu \mathrm{g} / \mathrm{ml}$.

lumetric flask. The solution was sonicated and filtered through whatman filter paper and resulting solution was diluted with the mobile phase to get a working standard solution of $25 \mu \mathrm{g} / \mathrm{ml}$ of duloxetine hydrochloride.

\section{Calibration curve}

The quantitative determination of the drug was accomplished by a standard method. The column was equilibrated with the mobile phase for at least 30 min prior to the injection of the drug solution. Linearity of the peak area response was determined by taking measurement at six concentration prints ( 6 replicates at each point) working dilution of duloxetine hydrochloride in the range of $20-120 \mu \mathrm{g} / \mathrm{ml}$ were prepared by taking suitable aliquots of working standard solution in different $10 \mathrm{ml}$ volumetric flasks and diluting up to the mark with the mobile phase. Twenty micro lot quantity of the dilution was injected each time in to the column at a flow rate $1.0 \mathrm{ml} / \mathrm{min}$. Each dilution was injected 6 times into the column. The drug in the elutes was monitored at $230 \mathrm{~nm}$ and the corresponding chromatograms were obtained. Form these chromatograms the mean peak areas were calculated and a plot of concentration over the peak area was constructed. The regression of the plot was completed by least squares regression method. A linear relationship in the range was found to the $20-120 \mu \mathrm{g} / \mathrm{ml}$ of the drug between the concentration of duloxetine hydrochloride and respective peak area. This regression equation was 
Table 1: Calibration data of the proposed method.

\begin{tabular}{cc}
\hline $\begin{array}{c}\text { Concentration of duloxetine } \\
\text { hydrochloride }(\boldsymbol{\mu g} / \mathbf{m l})\end{array}$ & Mean peak area $(\mathbf{n}=\mathbf{6})$ \\
\hline 20 & 1244.002 \\
40 & 2371.692 \\
60 & 3647.656 \\
80 & 4977.042 \\
100 & 6136.990 \\
120 & 7299.147 \\
\hline Concentration range $=20-120 \mu \mathrm{g} / \mathrm{ml}$ & Slope $(\mathrm{m})=61.287$ \\
Correlation coefficient $\left(\mathrm{r}^{2}\right)=0.99970$ & Intercept $(\mathrm{b})=-10.1785$
\end{tabular}

later used to estimate the amount of duloxetine hydrochloride in pharmaceutical dosage form. A representative chromatogram for the separation of duloxetine hydrochloride is given in figure 1.

\section{Sample solution}

Twenty tablets of duloxetine hydrochloride were weighed and powdered uniformly in a mortar. An accurately weighed portion powder equivalent to $100 \mathrm{mg}$ of duloxetine hydrochloride was transferred into $100 \mathrm{ml}$ volumetric flask. The contents of the flask were sonicated for about $15 \mathrm{~min}$ for complete solubility of the drug and the volume was made up to $100 \mathrm{ml}$ with mobile phase. Then the mixture was filtered through a $0.45 \mu \mathrm{m}$ membrane filter. From the above solution $1 \mathrm{ml}$ aliquot was taken into a separate $10 \mathrm{ml}$ volumetric flask and diluted up to the volume with the mobile phase and mixed well. The above solution $(20 \mu \mathrm{L})$ was then injected six times into the column. The mean peak area of the drug content in the formulation was calculated by the regression equation of the calibration plot.

\section{RESULTS AND DISCUSSION}

The present study was aimed at developing a sensitive, precise and accurate HPLC method for the
Table 2: Accuracy data (triplicate values at 80, 100, 120 percent levels).

\begin{tabular}{cccc}
\hline $\begin{array}{c}\text { *Amount } \\
\text { taken }(\mu \mathrm{g})\end{array}$ & $\begin{array}{c}{ }^{*} \text { Amount } \\
\text { found }(\mu \mathrm{g})\end{array}$ & $\begin{array}{c}\text { *Percent } \\
\text { recovery }\end{array}$ & $\begin{array}{c}{ }^{*} \text { Mean percentage } \\
\text { recovery }\end{array}$ \\
\hline 90 & 89.14 & 99.04 & 99.04 \\
110 & 109.16 & 99.23 & 99.23 \\
130 & 128.80 & 99.08 & 99.08 \\
\hline
\end{tabular}

*Each value is a mean of three readings

analysis of duloxetine hydrochloride in bulk and in pharmaceutical dosage form and forced degradation. In order to achieve optimum separation of the component peaks, mixtures of buffer with methanol in different combinations were tested as mobile phase on a kromasil $C_{18}$ stationary phase. A binary mixture of buffer: methanol in a proportion of 85:15 $\mathrm{v} / \mathrm{v}$ was selected as the chromatographic peaks were well defined and resolved with no tailing. The retention time obtained for duloxetine hydrochloride was $3.443 \pm 0.06 \mathrm{~min}$. Each of the samples was injected Six times and the Sample retention times were observed in all cases. The peak areas of duloxetine hydrochloride were reproducible as indicated by low coefficient of variation. A good linear relationship $\left(\mathrm{r}^{2}=0.99970\right)$ was observed between the concentration of duloxetine hydrochloride and the respective peak areas. The regression curve was constructed by linear regression fitting and its mathematical expression was $y=61.287 x-10.1785$ (Where $y$ gives peak area and $x$ is the concentration of the drug). The regression characteristics are given in table 1 . When duloxetine hydrochloride solutions were analysed by the proposed method for finding out intra and inter-day variation, low co-efficient of variation was observed. The absence of additional peaks indicated non-interference of common excipients used in the tablets.

Table 3: Robustness study.

\begin{tabular}{|c|c|c|c|c|c|c|}
\hline \multirow{2}{*}{$\begin{array}{l}\text { Drug } \\
\text { name }\end{array}$} & \multirow{2}{*}{ Variations } & \multicolumn{5}{|c|}{ Chromatographic parameters } \\
\hline & & Retention time & Area & Height & Theoretical plates & Asymmetry \\
\hline \multirow{8}{*}{ 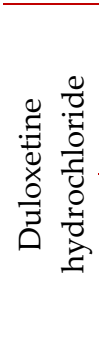 } & Change in wave length at $\pm 2 \mathrm{~nm}$ & & & & & \\
\hline & 1.wave length at $228 \mathrm{~nm}$ & 3.430 & 6247.732 & 728.039 & 3666 & 1.714 \\
\hline & 2.wavelength at $230 \mathrm{~nm}$ & 3.437 & 6283.478 & 724.787 & 3503 & 1.655 \\
\hline & 3.wavelength at $232 \mathrm{~nm}$ & 3.430 & 6363.381 & 735.321 & 3666 & 1.714 \\
\hline & Change in flow rate at $\pm 0.1 \mathrm{ml} / \mathrm{min}$ & & & & & \\
\hline & 1. flow rate at $0.9 \mathrm{ml} / \mathrm{min}$ & 4.110 & 7498.414 & 739.806 & 3656 & 1.727 \\
\hline & 2.flow rate at $1.0 \mathrm{ml} / \mathrm{min}$ & 3.437 & 6283.478 & 724.787 & 3503 & 1.655 \\
\hline & 3.flow rate at $1.1 \mathrm{ml} / \mathrm{min}$ & 2.940 & 5411.549 & 718.573 & 3518 & 1.680 \\
\hline
\end{tabular}


Table 4: System suitability parameters.

\begin{tabular}{cc}
\hline Parameters & Value \\
\hline Theoretical Plates $(\mathrm{h})$ & 3702 \\
Tailing factor $(\mathrm{T})$ & 1.71 \\
LOD $(\mu \mathrm{g} / \mathrm{ml})$ & 0.905 \\
LOQ $(\mu \mathrm{g} / \mathrm{ml})$ & 2.742 \\
\hline
\end{tabular}

High recovery values obtained from the different dosage form by the proposed method indicates the method is accurate. The drug content in tablets was quantified using the proposed analytical method are given in table 2 . The deliberate changes in the method have not much affected the peak tailing, Theoretical plates and the percent assay. This indicated the robustness of the method. The robustness study results are presented in table 3. The lowest value of LOD and LOQ as obtained by the proposed method indicates the sensitivity of the method. The standard solution of the drug was stable up to 24 hrs as the difference in percent assay during the above period is within limit system suitability parameters were studied with six replicates standard solution of the drug and the calculated parameters are within the acceptance criteria. The tailing factor and the number theoretical plate are in the acceptable limits. The system suitability results are shown in table 4 .

The system precision was established by six replicate injections of the standard solution containing analytes of interest. The value of relative standard deviation was found to be 0.322 which is within the limit, indicating the injection repeatability of the method. The method precision was established by carrying out the analysis six times using the proposed method. The relative standard deviation was found to be 0.268 which is within the limit, indicating the injection repeatability of the method.
The specificity of the HPLC method was determined by the complete separation of duloxetine hydrochloride. When it was subjected to forced degradation as per ICH guidelines, carried out with $0.1 \mathrm{~N} \mathrm{HCL}$, $0.1 \mathrm{~N} \mathrm{NaOH}$ and Heat degradation at $105^{\circ} \mathrm{C}$. The method does not permit detection of degradation product for duloxetine hydrochloride. The results of specificity data for degradation study are given in table 5.

Hence it can be concluded that the proposed HPLC method is sensitive and reproducible for the analysis of duloxetine hydrochloride in pharmaceutical dosage form with short analysis time of $5 \mathrm{~min}$.

\section{ACKNOWLEDGEMENT}

The authors are thankful to M/s Orchid Laboratories, Chennai for providing a gift sample of duloxetine hydrochloride and branded formulations. The authors are also thankful to Department of Pharmaceutical Analysis, Prist University, Thanjayur, Tamilnadu and Principal, Dr. K. V. Ramana and Correspondent, A. Siva Kumar, A.S.N Pharmacy College, Guntur (Dt), Andhra Pradesh for encouragement and providing laboratory facilities.

\section{REFERENCES}

Bhimanadhuni, C.N., Garikapati, D.R., Karamsetty, S. (2012). Development and validation of RP-HPLC method for determination of Modafinil in bulk and dosage form. International Current Pharmaceutical Journal, (4): 77-80. DOI

Dahivelkar, P.P., Redasani, V.K., Bari S.B. (2010). Study of hydrolytic and oxidative behavior of duloxetine in aqueous solution by RP-HPLC. Journal of Global Pharma Technology, 2(8):19-23.

Table 5: Forced degradation.

\begin{tabular}{|c|c|c|c|c|c|c|c|}
\hline $\begin{array}{l}\text { Drug } \\
\text { Name }\end{array}$ & Condition & $\begin{array}{l}\text { Time } \\
\text { in } \\
\text { hours }\end{array}$ & $\begin{array}{l}\text { Retention } \\
\text { time (min) }\end{array}$ & Area & $\begin{array}{l}\text { Retention time of } \\
\text { additional degra- } \\
\text { dation peak (min) }\end{array}$ & $\%$ Degradation & $\begin{array}{c}\% \text { of Active drug } \\
\text { Present after De- } \\
\text { gradation }\end{array}$ \\
\hline \multirow{4}{*}{ 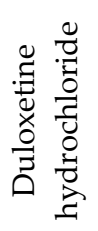 } & Control Sample & 00 & 3.437 & 6283.478 & 3.150 & - & 100 \\
\hline & Acid Degradation & 24 & 3.437 & 6237.208 & 6.500 & 0.73 & 99.27 \\
\hline & Alkaline Degradation & 24 & 3.460 & 5906.601 & 2.987 & 6.00 & 94.00 \\
\hline & Thermal Degradation & 24 & 3.427 & 5924.547 & 3.020 & 5.72 & 94.28 \\
\hline
\end{tabular}


Dasari, S., Viriyala, R.K., Santosh, K., Kumari, A., Ravikumar B.V.V., Bisht, S.P.S. (2010). A validated RP-HPLC method for the analysis of duloxetine hydrochloride in pharmaceutical dosage forms, Pharmacie Globale (IJCP), 1(3): 1-3.

Dhaneshwar, S.S., Deshpande, P., Patil, M., Vadnerkar, G., Dhaneshwar, S.R. (2008). Development and validation of HPTLC method for estimation of duloxetine hydrochloride in bulk drug tablet dosage form. Indian Journal of Pharmaceutical Sciences, 70(2): 233-236. DOI PMid:20046720 PMCid:2792489

Lakshmana, P.S., Srinivasan, M., Thiyagarajan, S., Marina, Q. (2010). Determination of duloxetine hydrochloride in pharmaceutical formulation by HPLC with UV detection. International Journal of Chem Tech Research, 2(3): 14411444.

Lantz, R.J., Gillespie, T.A., Rash, T. J. Kuo, F., Skinner, M., Kuan, H-Y., Knadler, M.P. (2003). Metabolism, Excretion and pharmacokinetics of duloxetine in healthy human subjects. The American Society for Pharmacology and Experimental Therapeutics, 31(9): 1142-1150. DOI

Ma, N., Zhang, B.K., Li, H.D., Chen, B.M., Xu, P., Wang, F., Zhu, R.H., Feng, S., Xiang, D.X., Zhu, Y.G. (2007). Determination of duloxetine in human plasma via LC/MS and subsequent application to a pharmacokinetic study in healthy Chinese volunteers. Clinica Chimica Acta, 380(12): 100-105. DOI PMid:17316589

Mercolini, L., Mandrioli, R., Cazzolla, R., Amore, M., Raggi, M.A. (2007). HPLC analysis of the novel antidepressant duloxetine in human plasma after an original solid-phase extraction procedure. Journal of Chromatography B, 856: 81-87. DOI PMid:17572161
Olsen, B.A., Argentine, M.D. (1996). HPLC method development for duloxetine hydrochloride using a combination of computer-based solvent strength optimization and solvent selectivity mixture design. Journal of Liquid Chromatography \& Related Technologies, 19(12): 1993-2007. DOI

Raj, R.V.A., Ramesh, T., Kumar, A.P. (2011). A validated UV Spectrophotometric determination of an antidepressant drug - duloxetine hydrochloride from capsule formulations. International Journal of Pharma and Bio Sciences, 2 (1): 716-720

Senthamil, S.P., Gowda K.V., Mandal U., Sam S.W.D., Pal, T.K. (2007). Determination of duloxetine in human plasma by liquid chromatography with atmospheric pressure ionization - tandem mass spectrometry and its application to pharmacokinetic study. J Chromatogr B Analyt Technol Biomed Life Sci., 858(1-2): 269-275. PMid:17904920

The Merck Index, $13^{\text {th }}$ edition, Merck \& co., INC., Whitehouse station, NJ, USA, (2001), 3498.

Waldschmitt, C., Vogel, F., Maurer, C., Hiemke, C. (2007). Measurement of duloxetine in blood using HighPerformance Liquid Chromatography with Spectrophotometric detection and column switching. Ther Drug Monit, 29(6): 767-772. DOI PMid:18043474

Yunoos, M., Sankar, D.G., Kumar, B.P., Hameed, S., Hussain, A. (2010). Simple UV Spectrophotometric determination of duloxetine hydrochloride in bulk and in pharmaceutical formulations. E-Journal of Chemistry, 7(3): 785-788. DOI 